Waido Vila

\title{
Problemática del arte moderno
}

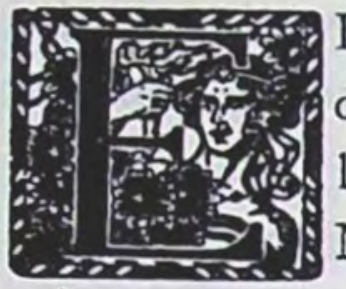

L PROCESO de lo que se ha dado en llamar Arte Moderno, ha creado entre los artistas una controversia, a la que desde luego el público no es ni puede ser ajeno. Naturalmente que todo esto aumenta el confusionismo existente, por cuanto los propios maestros del arte moderno de nuestros días niegan sus consecuencias y acusan a las generaciones jóvenes de haber desviado el arte hacia caminos sin salida. Hemos visto en nuestro ensayo anterior, "Declaraciones de Picasso y conceptos del arte moderno", publicado en "Atenea", N.o 369, página 334, declaraciones que no pueden ser tomadas a la ligera, ni tampoco es posible aceptar la sugerencia de ser negadas por su autor, como algunos han pretendido como última réplica. No hay nada de eso y me atrevería a decir que hay mucho más si tomamos en cuenta las declaraciones de Braque, creador, junto a Picasso, de la famosa Escuela Cubista; las de Chagal, padre espiritual del surrealismo que hablando propiamente, si algo se desea definir, sería en todo caso suprarrealismo porque lo otro resulta un desatino hasta en francés. Deberíamos, también, anotar las declaraciones de André Lothe, teorizante del cubismo, pero creo que antes debemos, por lo menos, soslayar la pregunta candente que es el contenido de este ensayo. ¿El Arte Moderno es un proceso de nuestros días o ha existido antes? La 
primera parte de la pregunta tendría, como una respuesta de circunstancia, la definición posible de arte moderno, considerándolo a éste, para todos los tiempos, como una reacción de cada época proveniente del cansancio de las formas de una etapa anterior, ya gastada y, por lo tanto, saturada en lo expresivo y plástico, haciéndose necesarios nuevos elementos, capaces de contener las ideas novedosas que comprenden la estética de la época; o sea, que las formas de una época de arte son a manera de moldes que contienen las ideas dentro de sí y cuando éstas están ya inutilizadas es de imperiosa necesidad su renovación. ¿Por cuáles otras? Ahí está el problema en todo su inquietante gravedad. Ya hemos vistos que la forma en arte es inseparable de la pintura. "Toda pintura es figurativa - nos dice el maestro del imprevisto, Pablo Picasso-, hasta las ideas metafísicas son figuras". Tiene razón el maestro, sin duda que la tiene, y los que carecen de ella son aquellos que además de usar impropiamente el lenguaje ignoran despreocupadamente las materias que tratan, con el desparpajo propio de los snobs. Veamos, si no, lo que se refiere a las formas en sí. La forma pura, amorfa, para poder existir debe tener un contenido que le dé su estructura como tal, porque sabido lo tenemos que ninguna forma puede existir sin un contenido. Es más, la célula misma de un organismo, para mantener su estructura poliédrica o exagonal, necesita de un elemento como el oxígeno, sostenedor de estructuras, de lo contrario, la célula se aplasta o se desintegra. En cuanto a la forma plástica se refiere, esto no es diferente y también necesita de un elemento de sostén, pues vacías de él no pueden existir. Este contenido puede ser religioso, filosófico o poético. Podemos querer ignorar muchas cosas, pero no podemos negar el proceso de la historia del arte, porque, en cierto modo, es la historia misma del hombre. Si observamos a través del tiempe la evolución de las culturas, veremos que casi todas nacen del caos: los asirios, babilónicos, egipcios y griegos. Las mismas culturas europeas, anteriores a la época del reno, nacen de un medio caótico y su primera expresión coordinada es el ritmo geométrico. A medida que la cultura avanza en su evolución y se hace, en cierto sentido, supe- 
rior, se enriquece y se transforma en pensamiento. Aparece, entonces, la forma y llega ésta a su plenitud cuando el hombre y la sociedad que la expresan han alcanzado su más alto nivel espiritual. La cultura egipcia, después de sus primeros intentos geométricos en las cerámicas arcaicas, alcanza con el Imperio Antiguo su más alto nivel cultural con el misterio de la filosofía esotérica que se atreve a desafiar a la muerte y proyecta sus esculturas estereométricas, aún no resueltas por los escultores modernos. Su mayor esplendor va unido a su más grande desarrollo espiritual: las formas matemáticas obedecen, para ellos, a un concepto del cosmos y le insuflan, por lo tanto a la forma, su eternidad misteriosa. En la cultura egea, primero, sucede otro tanto. Emerge del mundo obscuro del submar de la época mesénica y de los ritmos geométricos de la época anterior, alcanzando su grandeza casi divina en el siglo de Pericles, o sea, cuando el hombre está en plenitud en todos sus aspectos. Es entonces cuando aparece la escultura filosófica y los postulados de Fidias, que crea su estatuaria bajo las disciplinas de la sección áurea, la sabiduría del número de la filosofía pitagórica. Es la culminación del proceso ascendente de la forma, cuando su contenido es insuperable, religioso en los egipcios, filosófico en los griegos. Estas dos grandes culturas llegan a su período más alto de culminación y, después, decaen, cuando sus civilizaciones han entrado también en la decadencia. Ya no creen en los dioses, ni en sus principios filosóficos, entonces los egipcios se hacen académicos. Los herederos de los creadores de los Colosos modelan ahora pequeñas figurinas decadentes de bailarinas $\mathrm{y}$, por último, ni tan siquiera eso, vuelven a reaparecer las figuras geométricas en la cerámica como toda ornamentación.

En cuanto a la cultura griega, no sucede de otra manera. Los griegos se hacen también impíos como los egipcios, los filósofos de todo se burlan y todo lo destruyen con su dialéctica decadente. El artista ya no tiene en qué creer, o más bien, ya no cree en nada. Como una prueba evidente de todo èsto, está la Venus de Milo que por muchos años fué considerada como el arquetipo más puro del arte griego, o sea, del apogeo de la cultura del siglo $\mathrm{V}$, antes de 
Cristo, error que no es de extrañar cuando lo encontramos nada menos que en uno de los propios comentaristas de Worringer. Sin embargo, la realidad actual es muy otra. La famosa Venus mutilada fué creada como un desesperado intento de volver a las formas antiguas, ya perdidas en el período helenístico, por Xandro de Alejandría que copió un modelo de Scopas, desesperado en su tiempo de trivialidades, incapaces de crear las formas clásicas de los antiguos (consultar Worringer). Recurrió a las medidas y al modelo de Scopas, que no era ya ni la sombra de aquellos seres superiores que crearon la escultura filosófica, pero que aún así conservaba las medidas matemáticas de las enseñanzas de Fidias a sus discípulos. Después, y ya en plena decadencia, no pueden hacer ni eso y se limitan a copiar a los asirios y fenicios. Más tarde, nada.

Este es el proceso de una civilización que se levanta por alcanzar la plenitud de la cultura, partiendo de las simples formas geométricas llega a la plenitud de la forma. Cuando inician el proceso de decadencia, los elementos geométricos de nuevo afloran a la superficie y son incapaces de revivir los arquetipos de la antigua cultura que las hizo grandes. $\mathrm{Ni}$ las culturas más antiguas que podamos conocer, escapan a este postulado inexorable como los ritmos primitivos del hombre en su curso eterno. Los cazadores de reno, la más antigua civilización que tal vez se ha podido establecer, tampoco son ajenos a esos ritmos. Los pintores geniales de los bisontes hirsutos y de los caballos salvajes, desaparecen totalmente de la tierra algunos siglos antes del diluvio dejándonos el misterio inescrutable de su cultura. Después de este largo período geológico, sus descendientes del período neolítico, de la piedra pulida, se demuestran completamente incapaces de dibujar los frescos rupestres de Altamira o Dordogne de sus remotos antepasados; en cambio, su cerámica primitiva está decorada con simples elementos geométricos.

Si aceptamos este orden de ideas sólo como un planteamiento especulativo, para situar nuestra época en el tiempo de la historia, o sea, dentro del proceso que han seguido todas las culturas, porque no es en realidad otra cosa que la propia historia del hombre, como 
lo dijimos anteriormente, en condicionalidad del mundo que lo rodea y como su razón de existir. El arte de nuestro tiempo no puede, ni debe ser diferente frente a los factores determinantes de su época, porque serán ellos los que nos den la clave explicativa de éste; arte cada vez menos comprensible para el individuo no especializado en la materia como el arte de nuestros días, a llegado ha ser una especulación de técnicos, como una verdadera experiencia de laboratorio.

Se ha querido establecer una comparación entre la pintura de los antiguos y la nuestra. Analizada desde este punto de vista por Maurice Sachs, nos da una estadística impresionante: dice que es una época tan escasa de verdaderos pintores que puede ser comparada al período de gran escasez cultural que conoció Francia entre 1780 y 1820. Sin embargo, continúa, los pintores no faltan. Setenta mil en Francia; cuarenta y dos mil en Alemania; ciento cincuenta mil, quizá, en Estados Unidos. Pero, ¿y los grandes pintores? Solicitado por los aficionados (debemos leer snobs) que hacían la moda y por los comerciantes de quienes dependía la especulación, los pintores se habían descubierto fines en los que la pintura ya no tomaba parte. Admitamos como excusa a ello, continúa Sachs, que una época impaciente como la nuestra, contraria a la creación grave porque la pintura de hoy es superficial y los pintores no tienen el valor de privarse de la facilidad y porque no le dan importancia, cuando tienen amor al trabajo, sino a problemas más pequeños de la técnica pictórica (los más emprendedores, como vamos a ver, han sido teóricos que, queriendo ser puros, se han olvidado de ser humanos) $\left(^{*}\right)$. Debemos dejar establecido que, personalmente, no estamos de acuerdo ni en contra de estas discusiones y las citamos por creerlas de interés en el planteamiento de este ensayo desde nuestro punto de vista, previamente establecido al principio.

El proceso de la pintura, que nosotros conocemos como moderna y que, en todo caso, debemos consignar como contemporánea, se inicia algunos años atrás cuando la Escuela de París se dividió en

(*) Ensayo de Maurice Sachs. 
dos grandes grupos (apreciación de Sachs) que debemos considerar en forma muy generalizada. Unos, tomaron partido por la pintura abof tracta; los otros, por cualquier capilla particular a que hayan pertef necido, pueden ser considerados como del mismo lado, de los representativos o figurativos, como erróneamente se les designa (no hay pintura figurativa, etc... ver estudio anterior de Picasso). Se ha dicho que no se puede discriminar sobre unos con el testimonio de los otros. Si de éste grupo eran los más inteligentes, los que nos han dado la pintura racionalista, que quería, con Picasso, Braque, Leger a la cabeza, la pintura pura, y para alcanzarla había que evitar toda anécdota. En algunos años, como lo vimos en las declaraciones de Picasso, todos los motivos fueron burlados, las formas representativas eliminadas y no nos hablaron más que como una alusión. El cubismo existió hace unos veinticinco años, más o menos, y como resultado de no querer representar nada llegaron a la esterilización total y corrieron el riesgo, como lo hizo notar Picasso, advirtiéndoles del peligro de transformarse en unos geómetras estúpidos. Los cubistas no dejaron sus testimonios más durables en la pintura, pero más, en la estética de su tiempo y en la arquitectura, en el mueble de moda, en la línea del automóvil aerodinámico, o sea, crearon la moda de su tiempo. Desde ese instante se había caído en la locura colectiva de la postguerra, ya nadie sabía lo que era la pintura. La influencia del mago Picasso, del misterioso Picasso, ha sido discutida acaloradamente de ambos lados de la barrera; mientras unos lo consideran un genio, otros lo ponen como el símbolo falso de nuestra época. ¿Quién tiene la razón? Difícil es decirlo, sólo el tiempo, decantador de valores, le dará su verdadera estatura en la pintura de nuestro tiempo. Se ha llegado a decir que el maestro de la Escuela de París no se ha acercado jamás a la pintura de materia, la que se considera como la pintura verdadera, sino muy joven en Madrid y en París en 1926; cuando ha querido pintar pintura, lo ha hecho más mal que nunca, dicen sus detractores. El primer retrato de su mujer, o de una de ellas, por lo menos, a la manera de Ingres; y el segundo de ellos, que obtuvo el premio Carnegie, que sin su firma 
no resultaría ni en el Salón de Otoño (Maurice Sachs). No hay para qué insistir; después de varios años transcurridos desde esas polémicas se ha vivido bajo la influencia del brujo de Ballauri como bajo un artículo de fe $\mathrm{y}$, ahora, las opiniones sobre el maestro no pueden ser más contradictorias. Si bien unos lo endiosan, los otros lo consideran como un estafador. "El caso Picasso" sólo puede ser encarado como uno de los factores de lo que se considera la crisis del arte de hoy, que algunos, como René Huygues, conservador del Museo de Louvre, o algo por el estilo, y desde luego la opinión actual más interiorizada en pintura la ha denominado: "el fondo de saco de la pintura de nuestros días”. Encrucijada sin salida de la pintura moderna, llegando a decir que se trata de la agonía de la pintura. Lo importante es dejar establecido que la pintura actual sufre, indudablemente, una decadencia en su crisis interna, que se conjuga con una crisis del arte en la sociedad. Nunca como ahora el público ha estado tan distante de la pintura, como jamás antes lo estuvo en épocas anteriores. Ya nadie sabe lo que es la pintura, o lo que debiera ser, ni tan siquiera los pintores profesionales. El arte está demasiado separado de la vida, ha llegado a ser sólo una afirmación racionalista, individualista, casi una afirmación personal, una sutileza intelectual para no perder su prestigio esencial.

Podemos ver en Worringer, "Arte abstracto y naturaleza", que el arte naturalista se da en el caso del hombre que vive en feliz concordancia con el mundo, como en la gran época de Pericles; la tendencia a la abstracción ocurre en civilizaciones cuya actitud espiritual es completamente opuesta y en la que prevalece un sentimiento de separación, de desarmonía entre el ser humano y la naturaleza, tal como aconteció con los egipcios. O sea, que Worringer afirma, en el libro citado, que el arte es la expresión del mundo externo a través del hombre interno, que debemos hacer notar, fué nuestra premisa al plantear este ensayo. Me parece, entonces, necesario establecer cuáles serían los factores más importantes que producen la disconformidad del hombre actual con su tiempo. El hombre moderno, en cuanto a su armonía interior, está desconectado de 
sus íntimas esencias vitales; está vacío de amor por sus creaciones, es más, sus energías solicitadas por lo esencial se apartan de ellas como de algo superfluo, perdiendo con ello el equilibrio, prefiriendo a los valores que lleva en él, los valores artificiales fabricados por él. Los nuevos dioses que se ha dado a sí mismo: la ciencia, la economía, el industrialismo sistemático, el crédito (más que capital), nos dice Huygues, todos estos autómatas sin alma, marchando solos, como otros tantos Frankestein, perdían progresivamente a la humanidad de sus orígenes, convirtiéndose en ciegos mecanismos abstractos, siguieron su destino implacable e imprevisto, no el que se suponía haberles fijado. El hombre pequeñito, como en "Tiempos Modernos" del genial Chaplin, está desamparado entre estos monstruos creados por él, que amenazan devorarlo. Crea el arte abstracto como una evasión, a manera de una paradoja cruel. La crisis de la cultura es la crisis del mundo actual, su decadencia es también la decadencia del arte, pues hemos aceptado que el arte no es un fenómeno aislado. El arte tiene también su crisis interna, o sea, que atraviesa por las mismas incertidumbres que la época entera. Se ha dicho que el arte moderno se ha desvirtualizado por el espíritu de especialización metódica, el arte moderno ha querido adueñarse de los problemas estéticos, analizándolos por el espíritu de especialización metódica. Son, en otra versión, las mismas palabras de Picasso al criticarle a los artistas jóvenes "la preocupación de investigar que ha hecho que se extraviara la pintura y que el artista se perdiera en lucubraciones mentales". De esta manera, los artistas modernos han despejado algunos problemas plásticos, constructivos o expresivos, que han hecho más asequibles, aislándolos, y que luego han agotado, al concentrar todos sus esfuerzos sobre cada uno de ellos (Huygues). Estas experiencias son bien evidentes como los resultados del arte de nuestro tiempo. El fauvismo ha explotado, hasta el exceso, la transcripción de la vida personal, proyectando al máximo lo emocional; el cubismo, la transcripción de la plástica; el suprarrealismo, la exploración del subconsciente encerrado en la personalidad humana, liberando el instinto en sus formas más tremendas. Detrás de ellos, no dejan na- 
da. Esta es la tremenda tarea de los jóvenes a quienes les toca la herencia de continuarlo cuando no hay nada que continuar. Pero creo que este problema terrible de la juventud europea, destruída y desangrada por dos guerras, no es ni puede ser el de las juventudes de los países nuevos, plenos de posibilidades, que aún no han dicho su palabra porque vienen naciendo a la vida del arte. Cada país debe mirar lo propio, sus ríos, sus volcanes, las leyendas de su tierra, la vida pletórica. No debemos suicidarnos antes de haber vivido la propia vida. Por el contrario, es necesario amar lo nuestro, redescubrirlo, volverlo a crear en la plástica.

Todo gran período de arte ha tenido unidad plástica y la estrella tutelar de un maestro que la singulariza. Podemos tomar, indistintamente, algunas épocas y algunos nombres: Goya ocupa toda su época y la pinta con furia inusitada, termina con su siglo y alcanza a pisar el nuevo, cuando en París se levanta la estrella de Delacroix que llenará la época romántica. Picasso inicia el nuevo siglo, llega a París en 1901, pero este dios polifacético dice la palabra mágica, pero no puede encarnar por sí sólo a la gran figura que esperamos como el pintor del siglo veinte, en el cual la pintura se nos presenta como un gran espejo quebrado en el que, cada trozo, refleja un algo de belleza, vale decir, de verdad. ¿Cuál será el pintor de este siglo, que lo abarque y lo posea? No lo sabemos. ¿Lo dará América, Australia o la vieja Europa? Quién sabe si en este continente de ojos oscuros, abismados bajo el signo de la Cruz del Sur, ha nacido ya un niño moreno, de ojos antipodianos, que traza con su pequeña mano los primeros dibujos infantiles, que nos asombran y encantan en las muestras de niños. Yo desearía, con fe de pintor, que este niño naciera en algún remoto rincón de Chile, con rumor de río y olor a montaña de robles milenarios. 